\title{
The Body in Expressions of Emotion: Kuot
}

\author{
Eva Lindström \\ Research Centre for Linguistic Typology, La Trobe University, and \\ Department of Linguistics, Stockholm University \\ evali@ling.su.se
}

\begin{abstract}
This contribution examines the use of body terms in expressions of emotion in Kuot, a nonAustronesian language of New Ireland, Papua New Guinea. It is found that expressions involving the word for 'stomach', dalap, correspond mainly to what we would consider to be psychological states, while expressions making use of neip 'skin; body' are largely concerned with physical states. Some other body parts also form part of emotive expressions.
\end{abstract}

Many languages of Papua New Guinea make extensive reference to bodyparts such as the stomach and the skin in expressions of emotion, and this is found to a degree also in Kuot. Other parts of the body used in similar expressions, but to a lesser extent, are the lung/liver, eyes, hair and spirit. Each of these will be introduced in the sections to follow. There is also a brief discussion of similarities and dissimilarities with Tok Pisin expressions, and a list of Kuot predicates for emotions and feelings that do not refer to body parts is included for completeness. Further, some expressions for bodily states such as hunger and sickness are given. The data is then discussed in view of similar examples from other languages.

The data presented here was collected during 15 months of linguistic fieldwork for a doctoral dissertation on the grammar of the Kuot language (Lindström forthc.).

[NOTE 1] The examples are taken from recorded narratives, and from notes made at an elicitation session devoted to collecting body parts in idiomatic expressions and discussing their meanings. In order to make the examples easier to follow, I will start by introducing some facts about Kuot.

\section{Kuot}

Kuot is the only non-Austronesian language of New Ireland Province, Papua New Guinea, and is an isolate. It has some 1,500 speakers. The basic order of core constituents is VSO (although S and O are often not expressed as noun phrases). One core argument noun phrase can be fronted, indicated by the relator (RELR) lo, or ga (normally translated 'and'). Syntactic relations are further signalled by the obligatory cross-referencing of subjects and objects on the verb. The order of cross-referencers in relation to verb stems and each other is lexically determined, giving three verb classes, and does not influence semantics. There is further a closed class of adjectives, syntactically verb-like but morphologically distinct. [NOTE 2]

There are three numbers: singular, dual and plural. Singular nouns are either feminine or masculine. On nouns, the form used for plural referents will be glossed 'nsg' for non-singular, as that form is also the basis for the dual form (e.g. sg gas, nsg gasip, dl gasipien 'story'). Some nouns have only plural forms, including neip 'skin' and dalop 'stomach' which will figure prominently in the following. The same gender/number categories as for nouns are reflected in pronominal markers $(\mathrm{m} / \mathrm{f} / \mathrm{dl} / \mathrm{pl})$, with the masculine-feminine distinction only in the third person singular, and an additional inclusive-exclusive distinction in the first person dual and plural. In agreement and 
cross-referencing morphology the plural is not included in the dual form, and they will be glossed as dual $(\mathrm{d} / \mathrm{dl})$ and plural $(\mathrm{p} / \mathrm{pl})$.

There are inalienable and alienable possessive markers. The inalienable series (PossI) is used for body parts and any other part-whole relations, as well as for material, instrument, typical property etc.; the alienable series (PossII) is used with kin relations and all manner of ownership, as well as in certain benefactive uses. The inalienable possessives cross-reference the possessor in terms of the pronominal categories given above; the alienable cross-reference both the possessor and the possessed for the same categories. The construction is [possessed marker possessor] (e.g. examples (4a) and (22) below); both sets of possessive markers can also function pronominally, with the possessor left out (e.g. examples (1) and (3)), which is the most common construction in 1 st and 2 nd person.

Several adverbial and aspectual enclitics attach to the first constituent of a phrase (where the continuous particle man does not count for determining predicate-initial position). In the following, noun phrases and predicate phrases consisting of more than one word will be indicated with square brackets.

\section{Stomach}

We will now turn to the presentation of Kuot expressions with body parts. Since 'stomach' and 'skin' are the most frequent, these will be introduced first, followed by 'lung/liver', 'eyes' and 'hair'.

Kuot has two words for stomach, karima (masc) and dalap (nsg). Both can be used as a location for stomach ache etc., and in reference to the insides of the abdomen in general. However, in normal usage, karima tends to be used mostly of the stomach as a location for physical disorders, and dalop as a seat of emotion.

First, anger is a matter of one's stomach 'getting up', with daləp as subject of the verb 'get up': [NOTE 3]
(1) Te-me-aro
[dalop
o]
get.up-3pS-stm 2 stomach.nsg 3f.PossI
'she got angry' [lit. 'her stomach got up']

Correspondingly, there is a construction with a verb -ia meaning 'upset' (also as in 'stir up dust') and 'stomach', which means to annoy or irritate someone, usually taken to mean that it is done on purpose. Here dalap is the object of the verb and the irritated person ('her') is coded as the possessor of dalop:
(2) $u$-ia-am
$[$ dalop
$o]$
$3 \mathrm{mS}-$ upset-3pO stomach.nsg 3f.PossI

'he annoys her' [lit. 'he upsets her stomach']

To say that the 'stomach is bad' is to indicate ill feeling. It has the main sense of being angry, but can be interpreted as a range of strong feelings, including jealousy for someone's possessions (or their wife). In the following example from a story about a 
young man who was killed, it indicates his father's wish for revenge. Dalop is the subject of the adjective 'bad':

(3)

$\begin{array}{llllll}\text { ma-u-o } & \text { Levati } & \text { todəy, } & \text { kira-im } & {[\text { dalop }} & \boldsymbol{a}] \\ \text { come.from-3mS-stm } 2 & \text { L. } & \text { down/NW } & \text { bad-pl } & \text { stomach.nsg } & 3 \mathrm{~m} . P o s s I\end{array}$

me [ $\left.\begin{array}{ll}\text { poi } & \text { ay}\end{array}\right], \quad g a \quad m u-u-o$,

for child $3 \mathrm{~m}$. PossII.3s and come- $3 \mathrm{mS}-\mathrm{stm}_{2}$

[nәто ти-а-о $\quad$ a-nәти- $\eta]$ Apolos o naip. want come-3mS.fut-stm 2 .fut $3 \mathrm{mS}$.fut-kill-3sO.fut A. 3f.PossI knife(f) 'Levati came from down there, he was really upset about his son, and he came, he wanted to come (and) kill Apolos with a knife.' [lit. 'his stomach was bad']

The expression 'bad stomach' can be used for sickness to the stomach as well, but in the emotional sense only dalap can be used here, and not the other word for 'stomach' (karima).

The following example conveys a similar idea, but with dalap in a prepositional phrase. The example is from a narrative about a bush spirit called Kalamarun who had lived and worked with the people of Panaras village for years, when a bigman called Beke accused him of being lazy. This upset Kalamarun considerably, and subsequent to the incident he returned to the bush never to be seen again. It is reported twice in the short narrative, first saying that the words spoken by the bigman were bad, and not good in Kalamarun's stomach; then the other way around, that the words were not good, they were bad in his stomach:

(4) a.

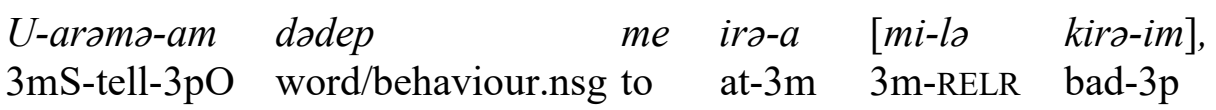

[tole mu-mur-um] na [dalop a $\quad$ Kalamarun].

NEG RED-good-3p in stomach.nsg 3m.PossI K.

'He told bad words to him, they were not good in Kalamarun's stomach.'

b.

...ne-buk-li-la ga [tale mu-mur-um $]$ [mi-sik dadep]

REC-quarrel-3dS-stm 2 and NEG RED-good-3p 3p-DEM word.nsg

la u-arama-am Beke me ira- $a$,

RELR 3mS-tell-3pO B. to at-3m

kiro-im na [dalop a].

bad-3p in stomach.nsg 3m.PossI

'... they quarreled and those words that Beke told him were not good, they were bad in his stomach.' 
The stomach can also be heavy, which means sadness or serious worry, for instance in someone who stands wrongly accused. The expression uses the adjective for 'heavy', gigina- (with dal $\mu p$ as subject):

(5) gigina-m $[$ dalop $\quad a]$

heavy-pl stomach.nsg 3m.PossI

'he is worried/sad' [lit. 'his stomach is heavy']

Conversely, the absence of negative feelings is expressed by the opposites of the above. Thus the adjective laklak- 'light (of weight)' is used with dalap to indicate the absence of sadness or worry, and 'good stomach' means a peaceful mindset:
a. laklak-uom dalap
light-pl stomach.nsg
b. mu-mur-um dalap
'untroubled'
RED-good-pl stomach.nsg
'untroubled'

There is further a word for ease of mind, or peace from war, malina. This is often located in the stomach as well, here in a prepositional phrase:

(7) malina na dalap

peace in stomach.nsg

'peace of mind' [lit. 'peace in the stomach']

When used of peace in a group of people who have previously quarrelled, the construction 'peace in their midst' or 'peace among them' is often used, e.g. malina arabura ma 'peace middle 3p.PossI'.

The expressions above are idiomatic in the sense that the meanings of the combinations of 'get up', 'be bad' and 'be heavy' with 'stomach' cannot be directly computed from the component lexemes, but have to be known. Sometimes, more specific predicates, which may also be used of people, are construed with the stomach as subject. Compare the sentences in example (8), which occurred within a few clauses of each other. They are from a story of a man who gets help from a possum to get down from a breadfruit tree. He is sitting on the back of the possum, which is leaping from tree to tree, and he is afraid. (The verb te-arz 'get up' signals a new action or event.)

(8)

a. Te-u-aro mikana ga kuk-kup=oy lo $<>$, get.up- $3 \mathrm{mS}-\mathrm{stm}_{2}$ man and RED-shout $=3 \mathrm{mS}$ RELR

muana lo me-rau [dalop a $]$.

reason RELR 3pS-afraid stomach.nsg 3m.PossI

'The man started shouting as $<>$, because he was afraid' [lit. '...because his stomach was afraid']

b. Te-u-arə mikana ga u-rau.

get.up-3mS-stm 2 man and $3 \mathrm{mS}$-afraid

'He got scared.' 
In this case, then, the verb -rau 'be afraid' is used first with the man's stomach as subject, then of the man himself, with no perceptible difference in meaning. (In another version of the story (recorded by the brother of the speaker in (8)), when the possum and the man return to the ground, the speaker uses an expression introduced above, saying that Toia's 'stomach was good' (mumurum dalop a), indicating calm and relief.)

The stomach as the locus for good or ill feeling is not restricted to the individual human. Villages have stomachs too, and here the other word for 'stomach', karima, sometimes alternates with dalap. In the following example, the speaker is talking of the golden past of Panaras village, saying that the village was very big and there was traditional knowledge ('from the village') of communal spirit, and it made Panaras a good place. The conjunction $o$ 'or' is used to show that 'the stomach of the village' is a better choice of expression than the preceding 'village':

$$
\begin{array}{cllll}
\ldots \text { papot } & \text { ma } & \text { dadep, } & \text { onim na pianəm, } \\
\text { many } & 3 p . P o s s I & \text { word/behaviour.nsg } & \text { PROV in village(f) }
\end{array}
$$

$\begin{array}{lllllll}o & {[\text { karima }} & \text { o } & \text { pianom }], & \text { ga } & \text { bet=iey } & {[\text { pianəm }} \\ \text { or } & \text { stomach }(\mathrm{m}) & \text { 3f.PossI } & \text { village(f) } & \text { and } & \text { arrive=3fS } & \text { village(f) }\end{array}$

lo mu-mur-u].

RELR RED-good-3f

'(There were) lots of words (/rites) from the village, or the stomach of the village, and a village (that was) good resulted.'

Here, the expression na karima o pianzm was explicated for me as 'amongst the people of the village'. In the next example, another speaker continues the same topic, regretting the loss of traditional magic or rites. He expresses the latter thus (the expression dalap o pianzm here is the amended subject of $i$-onoy):

$$
\begin{array}{cll}
\text { (10) ... }[\text { dadema } & o & \text { pianəm }], \\
\text { word/behaviour } & 3 f \text {.PossI } & \text { village(f) }
\end{array}
$$

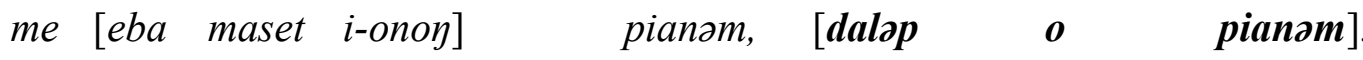

$$
\begin{aligned}
& \text { for FUT well 3fS-sit/live/stay village(f) stomach.nsg 3f.PossI village. } \\
& \text { '...village rite, for the village, the stomach of the village, to be well.' }
\end{aligned}
$$

It is worth noting in this context that the words for 'stomach' are never used in a spatial sense, e.g. for 'inside' etc. The expression 'the stomach of the village' is only used for the communal feeling; the village state of affairs in terms of harmony or disharmony among those who dwell there. This, then, can be seen as a case of metaphorical extension, where the village is the collection of people among whom the feeling exist (but note that pianzm is normally used for 'village' as a location; a collection of houses or a single homestead). In a simpler view, the expression could be taken as an abbreviated way of saying 'the stomach(s) of the people of the village', omitting the phrase 'of the people'. 
No apparent difference in the role of the words karima and dalop appear to result from the different syntactic constructions, with prepositions vs. as subject, or object, of a verb.

The last example of this section is a little different from the foregoing ones. It is about two boys who had always wanted to go shark-fishing but their mother said they were too small. Once they are big enough, they still have the urge and they go out ('up') to sea all the time in their canoe. The urge is expressed by the verb 'fir' which means 'scrape, grate, scratch' when transitive and 'itch' when intransitive, together with dalap:

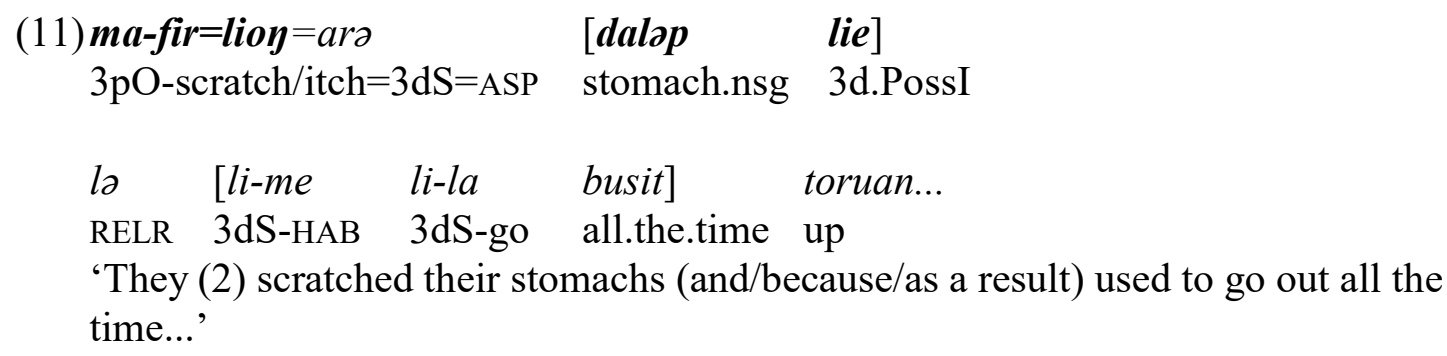

This construction is a little deviant in that the stomach here is not the subject but the object; although it expresses an urge that presumably emanates from inside, causing the boys to act, the grammatical relations are reversed, so that the boys are the subject of fir 'scratch; itch', and their stomachs the objects of the action. The Tok Pisin translation given to me displays the more expected relations: 'bel bilong tupela $i$ sikirap' (stomach POSS DUAL PRED scratch/itch, 'their stomachs itched'). Unfortunately I have no information as to the possibilities of reversing the relations in Kuot to something like 'their stomachs itched to go out'.

\section{Skin}

Also common in the region are expressions involving 'skin', where 'skin' frequently signifies the whole body. These are largely concerned with states that we would see as primarily physical. For instance, there are two expressions for feeling weak, listless or down, using Kuot neip 'skin' (nsg):
me-para neip
3pS-die skin.nsg
b. apa=mey neip numb $=3 \mathrm{pS}$ skin.nsg
[lit: 'the skin has died (is dead)']
[lit. 'the skin is numb']

The listlessness may be the result of states such as sorrow, sickness or fear. In the following example, a man sees a spirit woman, and goes weak with fear:

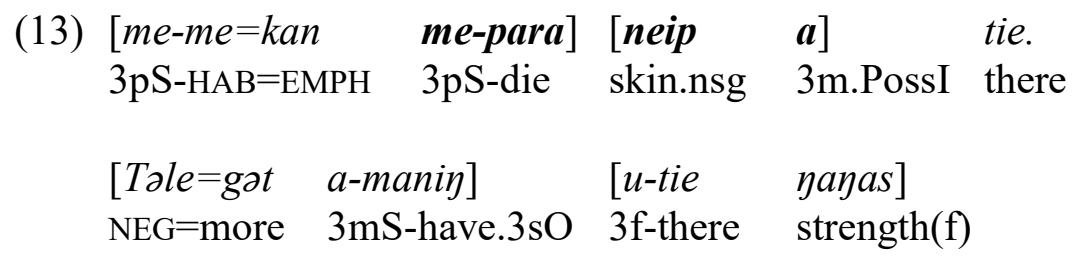




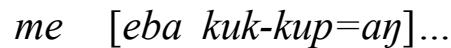

for FUT RED-shout $=3 \mathrm{mS}$.fut

'he went all weak. He didn't have the strength anymore to shout...' [lit. 'his skin really died there']

The skin can be heavy too, again signalling weakness. The speaker here uses a Tok Pisin lexeme 'pilim' ( $<$ feel-TR) rather than Kuot kasayən, with the adjective gigina'heavy':

(14) $[I-g a$

$$
\text { tafa }=t a \eta]
$$

ga ma-pilim=tuy $\quad[$ neip

tuo]

$3 \mathrm{fS}-$ be.about.to $\mathrm{sick}=1 \mathrm{sS}$.fut and $3 \mathrm{pO}-\mathrm{feel}=1 \mathrm{sS}$ skin.nsg 1s.PossI

\section{lo gigina-m.}

RELR heavy-pl

'I was about to get sick and felt weak.' [lit. '...I felt my skin (that was/being) heavy']

A word normally meaning to clear something, and also to break a house when tearing it down, durat, can also be used with 'skin' as its object in the sense 'make weak':

(15) ma-durat=iey pirom neip $3 \mathrm{pO}-$ break $=3 \mathrm{fS}$ sea(f) skin.nsg

'the sea makes you tired/weak' [lit. 'the sea wears out the skin']

The recovery of strength can be described as 'the skin coming back'. This example is from a story of a man who was severely beaten up and nearly drowned by malicious spirits. When they went away at daybreak, he dried himself on a stone in the sun and his strength started coming back:

$$
\begin{aligned}
& {[U-l a=r \quad m a n \text { te-balak=oy] tie, }} \\
& 3 \mathrm{mS}-\mathrm{go}=\mathrm{ASP} \text { CONT REFL-dry }=3 \mathrm{mS} \text { there, } \\
& {[\text { inə }=b \partial t \quad \text { me-na }] \quad\left[\begin{array}{ll}
\text { neip } & a
\end{array}\right] \text {. }} \\
& \text { again }=\text { now } 3 p S-\text { return skin.nsg } 3 \mathrm{~m} \text {.PossI }
\end{aligned}
$$

When the skin "gets up" or 'gets started', on the other hand, it means that the person is sexually aroused (see also 'hair' below):

\section{(17)}

$$
\begin{aligned}
& \text { te-me-ara neip } \\
& \text { get.up-3pS-stm } 2 \text { skin.nsg } \\
& \text { 'horny' [lit. 'the skin gets up/gets going'] }
\end{aligned}
$$

Just as 'stomach', 'skin' too can be used as the grammatical subject of appropriate conditions, which can alternatively be predicated of the human referent directly. The following two sentences are from the story of the man who got beaten up by malicious spirit beings; here he is explaining to his rescuer that he cannot climb up for coconuts as he is in such bad shape after being beaten up. Again, the sentences occur within a few clauses of each other: 
(18)

a.

...to-kira-i tiro, la to-me-nam kuraip.

1s-bad-sg here RELR 1sO-3pS-kill/injure spirit.being.nsg

'...I'm (in) bad (shape), (as) the spirits beat me up.' [lit. 'I'm bad here...']

b. Kira-im=kan [neip tuo] tiro.

bad-3p=EMPH skin.nsg 1s.PossI here

'I'm in really bad shape.' [lit. 'My skin is really bad here']

The fact that 'skin' in Kuot often equals what we would call 'body' is quite clear in the following example, which comes from an account of the speaker's trip to Lae on a passenger ship. After a week at sea, the passengers were not feeling very well: [NOTE 4]

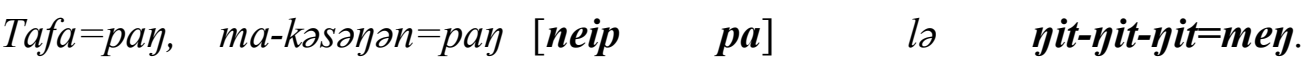
sick=1pxS 3pO-feel=1pxS skin.nsg 1px.PossI RELR RED-RED-hurt=3pS 'We were sick, we felt our skin really hurting.'

'Skin' also expresses other physical states, such as 'fever', which has no lexical expression, but is simply called pappamna-im neip, 'hot-pl skin.nsg - the skin is hot'.

\section{Lung/liver}

There are a couple of expressions involving the word for 'lung', basok (f). This is often translated by Tok Pisin 'leva', which means (and is derived from) 'liver' but can also refer more vaguely to other internal organs. The Kuot word for 'liver' is bakkarep, and when asked about the difference speakers always clarify that bosok is 'lung' (Tok Pisin 'waitleva') and bakkarep 'liver' proper. There are also some Tok Pisin expressions involving the liver, and there seem to be two possible sources for the confusion: first, it could be the result of the under-determinacy of the Tok Pisin word 'leva'; second, it could be that the Kuot word basok has both a strict anatomic reference ('lung') and a vaguer reference to the inside of the body. The issue will have to remain unresolved for the time being, and the lexeme will be translated 'lung/liver'.

To be worried is often expressed by 'the stomach is heavy' as we saw above, or simply "think a lot", but there is also an expression 'feed the lung/liver'. This makes use of a verb for 'give' which has the unmarked gift argument 'food', and here takes 'lung/liver' as the recipient argument. In this case it is a man who has just been seduced by a spirit who had taken the form of a woman from the village. When she turns into a flying fox and flies away, he knows that he is going to die and gets very very worried:

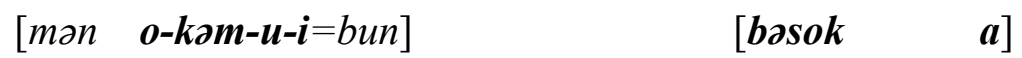

$$
\begin{aligned}
& \text { CONT } 3 \text { fO-give(food)-3mS-stm }{ }_{2}=\mathrm{EMPH} \text { lung/liver(f) } 3 \mathrm{~m} \text {.PossI } \\
& \text { 'he really worried' [lit 'he really fed his lung/liver'] }
\end{aligned}
$$

There is also an expression for discomfort or fear using bəsok. The whole expression is nakila basok (pronounced lakila basok by the speaker of example (21) below), but 
unfortunately I have not been able to get a clarification of the first element, which appears to be a predicate, judging from its syntactic behaviour. In this example, it indicates the fear of the man in (8), riding on the back of the possum:

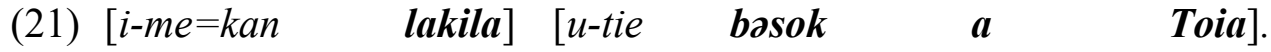 $3 \mathrm{fS}-\mathrm{HAB}=\mathrm{EMPH} \quad$ ? $\quad 3 \mathrm{f}$-there lung/liver(f) 3m.PossI T. 'Toia was really scared.' [lit. 'Toia's [that] liver was really ?-ing']

According to a different speaker, the typical use of the expression nakila basok would be for the kind of discomfort that results from people quarrelling or swearing close to you.

\section{Eyes}

To like or want something very much is to have 'bad eyes for it':
(22)
Kira-im [irap
o]
me $[$ dis
iey
Susanna].
bad-3p eye.nsg 3f.PossI for dish(f) 3f.PossII.3f S.
'She really likes/wants Susanna's bowl.'

This is different from 'jealous' (to have a 'bad stomach for something') above, which has negative connotations. To have 'bad eyes for something', on the other hand, is not threatening, and does not carry negative implications.

In a somewhat less idiomatic expression, a way of saying 'sleepy' is to say 'the eyes want to sleep':
$[$ namo $=r$
duri=mey $] \quad\left[\begin{array}{ll}\text { irzp } & a\end{array}\right]$
want $/$ be.about.to $=$ ASP sleep $=3 \mathrm{pS}$ eye.nsg $3 \mathrm{~m}$. PossI
'he is sleepy'

There is no lexicalised expression for 'sleepy'. It is possible to omit mention of the eyes, and just say 'he wants to sleep' (nəmo $=r d u r i=a \eta)$, which may mean either that he wants to go to bed, or that he is about to fall asleep anyway. Mentioning the eyes conveys the impression that he is overcome by sleep whether he wants to or not.

\section{Hair (of the body)}

I am aware of one expression involving hair. This is the other expression for being sexually aroused:

te-u-arz $\quad$ kapuruma
get.up-3mS-stm 2 hair(m)
'horny' [lit. 'the hair gets up']

The hair of the head is normally construed with the non-singular form of kapuruma: kapurup. My informant for this expression explained that in this case it is rather the body hair that stands up, as from cold, which makes the expression rather similar to the synonymous 'the skin gets up' above. 


\section{Spirit}

The word muranəma means 'spirit, ghost, shadow, portrait (etc.)' of a person. The following expression for fright means that the spirit leaves you:

(25) $u$-la $=r \quad[$ muranəma $a]$

$3 \mathrm{mS}-$ go $=$ ASP $\quad$ spirit $(\mathrm{m}) \quad 3 \mathrm{~m}$. PossI

'he was afraid' [lit. 'his spirit went']

\section{Another expression with neip 'skin'}

There is at least one other expression in Kuot which may be seen as relating to the cultural perceptions of body, although it does not refer directly to anything we would like to call emotion. The expression is 'bad skin' (which we saw above in the sense of being in 'bad shape'). This may be used of a person who has no luck in a particular activity:

(26) Kira-im [neip a i-sik], bad-pl skin.nsg 3m.PossI 3m-DEM

$$
\begin{aligned}
& \text { [tale }=k a n \text { u-me a-kof }] \quad \text { [abuluma ba }] \text {. } \\
& \mathrm{NEG}=\mathrm{EMPH} \quad 3 \mathrm{mS}-\mathrm{HAB} \quad 3 \mathrm{mO}-\mathrm{catch}=\varnothing \text { fish }(\mathrm{m}) \text { 'one' } \\
& \text { "'His skin is bad", he never catches any fish.' }
\end{aligned}
$$

Others would not want such a person to come along on a fishing expedition, as nobody would get any fish. [NOTE 5]

\section{A note on similar expressions in Tok Pisin}

All speakers of Kuot are bilingual in the regional creole language, Tok Pisin (one of the official languages of Papua New Guinea). Tok Pisin also has many expressions of emotion involving body parts, in particular 'bel' (stomach) and 'skin'. Some of them overlap with Kuot expressions, and this makes it difficult to know which overlapping expressions are the result of calquing (in either direction), and which overlap just because this is a common way of expressing emotion in this part of the world. The short comparison in Table 1 shows that while some expressions are directly translatable between the two languages, several others show a mismatch. The comparison is restricted to expressions involving 'stomach' and 'skin', and draws on the New Ireland variety of Tok Pisin. 
Table 1. Some Tok Pisin and Kuot emotive expressions with 'stomach' and 'skin'.

(n. neip, d. dalap, $=$ same translation)

\begin{tabular}{|c|c|c|c|c|}
\hline Tok Pisin & & Kuot & & Lit. transl. \\
\hline 'bel i kirap' & $\begin{array}{l}\text { 1. horny } \\
\text { 2. angry }\end{array}$ & te-me-ara $d$. & $\begin{array}{l}\text { angry } \\
\text { (*horny) }\end{array}$ & stomach gets up \\
\hline 'belhat' & angry & - & & stomach is hot \\
\hline- & & kira-im d. & $\begin{array}{l}\text { angry, upset, } \\
\text { jealous }\end{array}$ & stomach is bad \\
\hline 'belsore' & sad & kadik=mej $d$ & & stomach is sad \\
\hline 'belhevi' & sad, worried & gigina-m $d$. & $=$ & stomach is heavy \\
\hline 'belisi' & untroubled & $\begin{array}{l}\text { 1. laklak-uom } d \text {. } \\
\text { 2. molina na } d \text {. }\end{array}$ & $=$ & $\begin{array}{l}\text { stomach is } \mathrm{OK} \text {, } \\
\text { light, has peace }\end{array}$ \\
\hline 'gutpela bel' & untroubled & mu-mur-um d. & $=$ & stomach is good \\
\hline 'skin i dai' & $\begin{array}{l}\text { weak, } \\
\text { listless }\end{array}$ & $\begin{array}{l}\text { 1. me-para } n . \\
\text { 2. apa=mey } n .\end{array}$ & $=$ & $\begin{array}{l}\text { skin dies } \\
\text { (/goes numb) }\end{array}$ \\
\hline 'skin i les' & tired, fed up & ?palala $=$ mey $n$. & & skin is fed up \\
\hline $\begin{array}{l}\text { 'skin i } \\
\text { kirap' }\end{array}$ & horny & te-me-ara $n$ & $=$ & skin gets up \\
\hline
\end{tabular}

The first expression, 'bel i kirap', matches in one translation and not the other. For 'belhat' there is no direct translation in Kuot (*pappamna-im dalop, hot-pl stomach.nsg). I am not aware of a Tok Pisin expression *'bel nogut' for ill feeling in the New Ireland dialect to match the Kuot one on the next line, although this expression improvised would probably be understood. The seven following expressions match in meaning, although it may be pointed out that the morpheme 'isi' (<easy) in 'belisi' does not correspond directly to morphemes in either of the Kuot expressions.

\section{Related concepts expressed without reference to body parts}

There are a number of verbs (and a few adjectives) that encode states of the mind and body without particular reference to body parts, some of which overlap in meaning with those given above. The list in Table 2, although not exhaustive, is included in order to give an idea of the range of expressions in the language. [NOTE 6]

Table 2. Some verbs and adjectives expressing emotions and bodily states.

\begin{tabular}{|l|l|l|}
\hline Kuot & English & word class \\
\hline te-bo & be happy, rejoice & V III \\
\hline tepurus & be happy & V I \\
\hline bo-para & sympathise with; worry about & V III \\
\hline kadik & be sorry; mourn & V I \\
\hline palala & be fed up, tired of s.th. & V I \\
\hline muli-bə & be ashamed & V III \\
\hline -rau & be afraid & V II \\
\hline turup-abo & get a fright, be startled & V III \\
\hline tedif & be startled, start & V I \\
\hline mudurut & be afraid; shudder from anything & V I \\
\hline
\end{tabular}




\begin{tabular}{|l|l|l|}
\hline kukku- & be angry & adj \\
\hline mukmuka.- & be grumpy, sulk & adj \\
\hline te-buk & be jealous & V I (refl.) \\
\hline na & want (me 'for' N) & V I \\
\hline -maniy & want (N) & V II (irreg) \\
\hline -ga & want (V) & V II (aux) \\
\hline kikkis & not want (me 'for' N) & V I \\
\hline gayas & strong, strength & V I, N \\
\hline yana- & strong & adj \\
\hline malube & be weak & V I \\
\hline apa & be numb (of skin/other body part) & V I \\
\hline yit & hurt (of head etc.) & V I \\
\hline kasayan & feel & V I \\
\hline $\begin{array}{l}\text { te-kalappi; } \\
\text { te-pirit; } \text { te-ppirit }\end{array}$ & feel strong pain & V I (refl. only) \\
\hline o-rama & feel strong pain & \\
\hline men & 'high' from betelnut & V III \\
\hline ut & be full (fr food) & V I \\
\hline tafa & be sick (S. Kuot) & V I \\
\hline golai & be sick (N. Kuot) & V I \\
\hline susukun & feel cold & V I \\
\hline gos & feel (sticky) hot & V I \\
\hline
\end{tabular}

Other states lack lexicalised expression. Thus there are only periphrastic expressions for sleepy as in (23) above, as well as for 'hungry' and 'thirsty':

a. $t a f a=$ o me parak

sick $=3 \mathrm{mS}$ for food

'he is hungry' [lit. 'he is sick for food']

b. tu-ga top-ta-o

1sS-want drink-1sS.fut-stm 2

'I'm thirsty' [lit. 'I want to drink']

\section{Discussion}

We have seen in the foregoing how a number of nouns for body parts can be used in expressions of emotion in Kuot. The question arises as to whether for instance the word dalap 'stomach; insides" is "the same" when used as the location of physical pain, and when used as the seat of an emotion. The answer will depend on a number of factors. It depends on the particular language in question, the observed usage of the expression, and speaker perceptions. On a theoretical level it depends crucially on what exactly we are examining in terms of sameness/difference, and also on what our medium of comparison is. In the following, examples from other languages will be introduced. They are intended primarily to shed light on the Kuot data, rather than to address more general theoretical issues, and the same is true of the rest of the discussion which focusses on various semantic and syntactic aspects of the Kuot examples. 
First, the use of the expression in the language, and the perceptions of the speakers need to be considered before the linguist applies his or her interpretation. To illustrate this point, I would like to bring in the example of Estonian, [NOTE 7] where bodypart expressions and some other nouns have grammaticalised into postpositions. There are several local cases which can be roughly described in terms of an 'in' set and a 'surface' set, each with three dimensions: 'from', 'at', and 'to'. In other words, case distinctions alone are capable of showing differences such as 'from inside [it]' vs. 'onto the surface [of it]' and so forth. But in idiomatic speech it is highly unusual to find case alone signalling this information. Instead of

(Estonian)

(28) laua-le

table.GEN[NOTE 8]-onto

'onto the table'

and

(29) laua-lt

table.GEN-from.surface

'from the table'

we normally get constructions such as

$\begin{array}{ll}\text { laua } & \text { pea-le } \\ \text { table.GEN } & \text { head.GEN-onto }\end{array}$

'onto the table' [lit. 'onto the table's head']

and e.g.
laua
kõrva-lt
table.GEN ear.GEN-from.surface
'from the side of the table' [lit. 'from the table's ear']

The same type of construction is found also with, for instance, the words juur- 'root', $\ddot{a} \ddot{a} r$ 'edge, side', pool 'half' and käsi 'hand'. [NOTE 9] The constructions in which they appear are grammatically fully transparent and the lexemes involved retain their lexical senses alongside the postpositional ones. What is interesting to us here, is the fact that native speakers of Estonian are completely oblivious of the fact that they are the same words. Even when asked if pea 'on' is anything to do with pea 'head' speakers will give it some thought and then say "I don't think so", and only when faced with the set of words as a whole will they recognise the pattern.

Although the Estonian example is not directly pertinent to the discussion of expressions for emotion, there is an important point to be taken from it. The fact that the Estonian culture is firmly rooted in northern Europe gives little scope for suggesting that the Estonians have an "embodied" view of the world, or somehow conceive of tables as having heads and ears. We are looking at a linguistic convention, 
and there is no grounds for postulating exotic thought patterns as a reason for it, or indeed as a result of it.

At the other end of the spectrum, so to speak, we have the situation where an expression may seem idiomatic but does in fact reflect the speakers' perception of reality. Writing about Selepet, a Papuan language of Morobe Province in Papua New Guinea, McElhanon (1975) points out that in order to analyse idioms, the researcher needs a good understanding of cultural perceptions. For example, according to McElhanon, Selepet speakers believe that a foetus is formed by the mother's blood "gathering together" (pp 109-110), so when they say hepye tok yap 'her blood broke loose; she miscarried' this is simply a description of the facts of the event, as viewed by speakers. If we accept this position, this particular expression would thus not be an idiom, in that it can be understood in terms of its parts once the speakers' ideas about the physical world are known.

Although the example just given is not treated as an idiom by the author, Selepet certainly does not lack idioms, but has an elaborated system of combinations of a set of 28 body-part nouns with a set of predicates. Some combinations yield nonsense, but the majority of the remaining combinations do not appear to be interpretable in terms of the component parts, even when the cultural connotations of the nouns (and predicates) are known. Thus the meaning of hakne yâkâlen gâisap 'he hung his skin at her (place); he wants to marry her' presumably has to be known. That is, even if the expression makes sense in terms of the language and culture, its meaning is still not predictable from the parts. [NOTE 10]

Most of the 28 body-part nouns observed in idiomatic expressions in Selepet have particular associations with psychological and sociological functions. The words for 'belly' and 'insides' are to do with emotions, 'nose', 'head', 'ear' and 'tooth' with a person's disposition and social behaviour, and so forth. [NOTE 11] Within each group, each word again has its particular domain of use, so that biwi 'insides' is used of personal character, attitudes and frame of mind, and relations to immediate family, while tep 'belly' is more to do with socially mediated emotions. The term hâk 'skin' is used with similar properties to those expressed with biwi 'insides' but of a less permanent or "deep" type. As for the predicates, these can be varied not only to yield different properties for the various body parts, but also to give different degrees (i.e. 'is hot' vs. 'burns and blisters' of the insides mean 'angry' and 'very angry', respectively).

The main difference between emotions expressed with 'insides' and those expressed with 'skin' in Selepet is thus that the latter are more transient and/or less intense; "“skin' [...] expresses the superficiality in one's life" (p 121). The Melpa, or Hagen, language of the Western Highlands of Papua New Guinea also distinguish emotions that are 'on the skin' from emotions that are 'inside' but in a somewhat different way. Writing about it, Strathern (1975, also as Strathern 1977) focuses on 'shame' (pipil) and expressions such as 'there is shame on our skins'. He finds that an emotion that is 'on the skin' is a socially conditioned, public emotion, in terms of 'shame' resulting from such things as feelings of inadequacy or having been exposed as a liar, or observed in the act of sexual intercourse. A speaker explains to him that "[i]t is when people see us, it is not that there is anything inside" (1975: 349). It is socially expected 
and correct to feel shame on these occasions; further, 'shame' can be displayed on purpose, e.g. to avert anger. The same speaker contrasts 'shame on the skin' with 'anger' (popokl). 'Anger' is inside and either has to be brought out into the public sphere, or may cause sickness, either to the angered person or the wrongdoer, while 'shame', if 'on the skin', is harmless in this respect. We see how 'skin' is construed in Melpa as the social interface of a person.

The Wahgi, also of the Western Highlands of Papua New Guinea, have taken the notion of 'skin' even further, and judgments about skin (primarily in terms such as 'shiny' vs. 'dull') at ritual displays form an integral part of the cultural parlance about the moral status of the community (O'Hanlon 1989). [NOTE 12]

So how does Kuot compare with the examples given above? First, unlike the Estonians with their postpositions, any Kuot speaker will tell you that the dalop where the feelings are and the dalop that may hurt or which you cut open when butchering a pig are the same. The nature of this "sameness" deserves some discussion. I would say that physical versus emotional is not actually the best way to draw the line. This is because the exact location of internal pain is almost as vague as that of emotion, irrespective of how well you know your anatomy (and for instance, neither emotion nor most cases of pain is likely to be observable in the organs on autopsy). I would argue that anatomical knowledge is where the difference is, i.e. the knowledge of what internal organs there are, and their names and locations. Such knowledge is distinct from knowledge of the precise functions of these organs, and from knowledge about the diseases that can afflict them and the particular symptoms of those diseases, so that there is no conflict in having extensive anatomical knowledge and still having 'stomach pains' without being able to pinpoint the particular organ where the pain is located. [NOTE 13] It is interesting to note that the word 'stomach' in English has precisely that kind of polysemy, denoting on the one hand the organ in the upper area of the abdomen that receives food as it comes down the gullet, and on the other hand more vaguely the abdomen as a whole. When we say in English that we have a stomach ache, we normally use the word in the second sense, even if we are aware of the first sense and of other terms denoting internal organs and perhaps even know something of their functions. This is because most of us simply do not know the precise location and origins of the pain, even in our own bodies.

I would suggest then, that the sense of dalap 'stomach' in Kuot is similar for emotions and for pain, in that it refers to the insides of the middle part of the body in a general way. The part of the body that you cut up when butchering a pig has much the same physical extension, being the area comprising the internal organs, but may be conceptualised differently because butchering a pig involves seeing and handling the various distinct organs within the belly. This is perhaps clearer for bəsok 'lung/liver', which is somewhat parallel to the English word 'stomach' in having a specific anatomical reference and a vaguer more general one; in this case along the lines of 'lung' vs. 'some internal organ' (translated 'leva'/'liver'). [NOTE 14]

Compared with Selepet, the Kuot system is obviously much more restricted, involving fewer body parts combined with fewer verbs. All the same, there is a degree of specialisation, although this too is reduced in comparison with the more elaborated system of Selepet. We have noted how the 'stomach' is the locus of many 
psychological states, with 'lung/liver' as an alternative at least for feelings of fear and worry. We also saw in examples (22) and (3) that there is a definite difference in using the adjective for 'bad' with 'eyes', as compared with 'stomach'. 'Skin' on the other hand is to do mainly with general health and physical well-being. I have no indications that the state of the 'skin' is in any way directly connected to the moral state of the individual or the group as was the case among the Wahgi - the state of the 'skin' in Kuot refers to physical state of the person; whether he or she is strong and healthy, or without strength. As noted above, the cause of weakness may be things such as sickness or fear, and there may in turn be notions about the reasons for these, involving sorcery or other concepts which may lead us to perceptions of morality; my point is simply that the use of the term 'skin' in Kuot does not as such refer to morality, just to health. This goes also for the expression in (26), where 'bad skin' is used of someone who brings bad luck to a fishing expedition; this appears to have no connection to the morals or behaviour of the person in question, but is just an unlucky property that some people have. [NOTE 15]

Having made the generalisation that 'stomach' is about psychological states and 'skin' about physical ones, a question that arises is what it lets us infer for instance about perceptions of sexual arousal, which is expressed with 'skin' or 'hair'. Does that mean that the Kuots construe sexual arousal as a bodily rather than an emotional condition? That is precisely the sort of conclusion one would arrive at if we were to take the linguistic conventions in use in the language as an explicit and direct guide to the thought patterns and world view of the speakers. I would caution against such an approach: while there is a certain consistency in linguistically assigning feelings to particular parts of the body in Kuot, there may or may not be culturally mediated notions to the effect that those feelings actually reside there in some concrete sense. Establishing such a connection would be an area for careful anthropological investigation, and to take a single phrase (in this case expressions for 'horny') as evidence for cultural or cognitive notions of that kind would be precarious indeed. What is more, the same speakers quite happily locate the same feeling in the stomach when speaking Tok Pisin.

Turning now to those expression where the body-part noun can be omitted, we need to look the semantic impact of omission or inclusion. The majority of the Kuot expressions given above require both the body-part noun and the predicate to be present to give the required meaning. That is, example (1) would mean something different if the word dalop were not in it (namely 'she got up', te-i-arz). But a few other examples make use of a more specific predicate, which can be applied to a person or to a body part (in the latter case the person is grammatically coded as the possessor of the body part). The use of the body-part noun is optional in these cases, in terms of the overall meaning of the expression. This is the case in examples (8), (18) and (23) above.

It was noted at example (8) ('he is afraid' vs. 'his stomach is afraid') that there is no significant change in meaning; the expression means that the person is afraid whether his stomach is mentioned or not. Example (23) ('he wants to sleep' vs. 'his eyes want to sleep') is structurally similar and here it was stated that the version with the word for 'eye' implied less control. Although I have not been able to investigate it in detail, I would suggest that other cases where the body part is optional may be similar to the 
example with 'eye' in this respect. Although 'fear' is presumably not controllable under any circumstances, the use of the body part may have the function of conveying the impression that the person is overcome by the emotion.

In a similar example, the intransitive verb kadik is used with and without dalop, again within a few clauses. Kadik mostly means 'be sorry' but can also refer to other forms of empathy. The person for or about whom the feeling is expressed is coded with the preposition $m e$ 'for, to; about'. The example is from a letter (the writing has been brought into line with the standard used in other examples):

$\begin{array}{llllll}\text { Tara } & \text { la } & \text { pa-nu-lai } & \text { [mitara } & \boldsymbol{k a d i k = p a y}] & \text { no-i-me } \\ \text { time } & \text { RELR } & 1 \mathrm{pxO}-2 \mathrm{sS}-\mathrm{leave} & \text { very } & \text { be.sorry=1pxS } & \text { 2sO-near-to }\end{array}$

'When you left us, we were so sorry about you.'

b.

$\begin{array}{lllll}{[\text { mitara }} & \boldsymbol{k a d i k}=\boldsymbol{m e y}] & {[\text { dalop }} & \boldsymbol{p a}] & \text { no-i-me } \\ \text { very } & \text { be.sorry }=3 \mathrm{pS} & \text { stomach.nsg } & 1 \mathrm{px} . \text { PossI } & \text { 2sO-near-to }\end{array}$

tara lo pa-nu-lai to.

time RELR 1pxO-2sS-leave here

'Our stomachs were so sad about you when you left us here.'

Again, sorrow is not something that is normally controlled, [NOTE 16] and I suggest the "overcome" factor may be at play again, and perhaps an implication that the motion is deep-seated. However, this analysis remains speculative at the present stage of research.

Example (18) ('I am bad' vs. 'my skin is bad') utilises a less specific predicate which is equally illuminating for the role of body-part nouns. In (18) it would appear that the use of 'skin' in the second utterance clarifies that it is the subject's physical condition that is referred to (although in the first utterance this is inferrable from the statement that the spirits beat him up). When inquiring about the general condition of someone, the typical question and answer are the following, using the adjective mur- 'good':

(33) No-mur $-i=t$ ?

2s-good-sg=just

'(Are) you just fine?'
Aa, to-mur-i=t.

yes 1s-good-sg=just

'Yes, I'm just fine.

Functionally, this is equivalent to asking 'How are you?', and being more specific would be pragmatically marked. That is, if we would ask 'How are you feeling?' there would be implications to the effect that the person had been feeling unwell in some way. Similarly, Kuots do not ask each other whether their skin or stomachs are well. The question in (33) is therefore general enough to allow for a non-affirmative answer concerning either emotional or physical state ('OK, but I might be getting a cold' or 'OK, but I'm a bit sad since my auntie died').

I also want to comment on the verb kəsəyən 'feel'. This verb has the primary sense of perceiving by touching, but can also be used with body parts cross-referenced as 
object, and a clause introduced by the relator lo explaining what the matter is with the cross-referenced body part (as in (19), and in (14) with the Tok Pisin lexeme 'pilim'). It is also possible to have a reflexive form, with the reflexive prefix te-in the preverbal object slot. Two examples with te-ccuring close to each other in the same narrative show variation in the complementation strategy, the one using nomo in complementiser function (it can also mean e.g. 'say', 'want' and 'be about to'), the other using the relator. (The gloss FUT (and fut) stands for "future" but here corresponds to English 'would' in the past habitual sense):

(34)a.

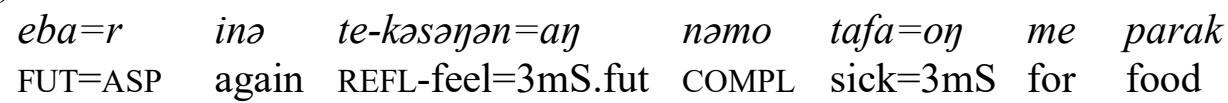
'he would feel hungry again' [lit. 'again he would feel himself that he was sick for food']

b. eba te-kasayən $=a \eta$ lo tafa $=$ oy me parak FUT REFL-feel $=3 \mathrm{mS}$.fut RELR sick $=3 \mathrm{mS}$ for food 'he would feel hungry' [lit. 'he would feel himself (that) he was sick for food']

I have no examples of this verb occuring with clearly emotional predications (although it is possible to imagine it used with an object such as 'stomach', parallel to examples (14) and (19) with 'skin'; however I think this would not be very idiomatic and the default interpretation would be that there was something the matter with the stomach i physical terms).

Even without kəsəyən 'feel', we have seen that there are several ways of expressing emotional concepts in Kuot: by specific lexemes referring to the emotion (e.g. 'be angry' and others given in Table 2); by idiomatic expressions involving body parts (e.g. 'the stomach gets up'); and by using the specific predicates applied to body parts (e.g. 'the stomach is afraid'). There are also more general expressions, such as 'I am well' in (33), and 'the village sits/lives/stays well' in (10).

In that situation, what is the role of body-part expressions? For the Australian language Yankunytjatjara, Goddard $(1994,1996)$ argues that the word tjuni 'belly, guts' is polysemous and means 'feel' in expressions like ngayulu tjuni palya 'I "belly" good = I feel good'. The basis of the argument is that there is no other way in Yankunytjatjara to say the equivalent of the English 'I feel good', and that the expression cannot be a metaphor because it cannot be explicated in other terms in the language. In Kuot, although 'my stomach is good' is probably the closest match to the English 'I feel good', for most emotive expressions alternatives can probably be found.

It is further the case that the word 'stomach' forms part of a whole set of expressions, many of which are idiomatic. This means that with a phrase such as 'I feel good' 'my stomach is-good' we can cancel out matching morphemes (' $\mathrm{I} / \mathrm{my}$ ' and '(be) good') and end up with 'stomach' = 'feel'. I realize that this is a crude and simplistic description of the procedure, but my point is that the result fails to take into account that there is an entire battery of expressions referring to emotions and utilising 
'stomach' but where the meanings of the words do not cancel out leaving 'stomach' = 'feel'. To take one example, in (5) above the morphemes giving the literal translation 'his stomach is heavy' do not mean 'he feels heavy' but 'he is/feels sad'. The meaning 'sad' or 'feel sad' results from the collocation. It is not clear to me why the expression 'my stomach is good' should not be analysed in a parallel way. [NOTE 17]

If we were to apply the Yankunytjatjara analysis to Kuot, it also appears that the lexeme given the meaning 'feel', splits in two when physical sensation is taken into account, since then 'skin' rather than 'stomach' is used.[NOTE 18], [NOTE 19]

The choice of expression is governed not only by semantic factors but also by pragmatic ones. For instance the expression 'stomach is good' is typically used in contrast to a negative state. This is the most general expression, and it was noted after example (8) that it was used by one speaker in contrast to 'afraid'. But where possible, opposites are often used, so that (6a) 'untroubled; the stomach is light' could also be translated 'I feel good', understood in contrast to 'worried/sad' which is expressed with the antonym of 'light', 'heavy'.

On occasion, 'stomach' is also contrasted with 'skin'. A man whose beloved had just left the area said '[it's] like she went (left) with my stomach and all my thought, and here I sit with just my (useless) skin' (unfortunately I was not able to note the expression down verbatim so I will not give it in Kuot here). The expression appeared to be improvised. It is interesting because it shows that 'stomach' and 'skin' can be used not only as conventionalised parts of expressions whose larger meaning is to do with emotion or health, but also themselves referring to those domains in a general way. It also shows how speaker creativity can employ means present in the language in new ways. Note that the sense of the terms 'stomach' and 'skin' is somewhat different here from earlier examples given. While 'stomach' does indicate the semantic domain of emotion, it is not a location here, nor does it translate as 'emotion'. What exactly would be a good translation is as difficult to pinpoint as the exact meaning of 'heart' in the old Tony Bennett song "I left my heart in San Francisco", and is beyond the scope of the present discussion. 'Skin' too is different here and, in being contrasted with 'stomach' (and 'thought') takes on a sense of 'container' not found in previous examples.

\section{Conclusions}

We have seen that there is a range of types of expression in Kuot for emotions. As regards those that make use of words for the body, we saw that there is a fair correspondence between expressions for internal parts of the body, such as 'stomach' and 'lung/liver', and emotions that would be considered psychological states in a Western tradition. Correspondingly, expressions with 'skin', also meaning 'body', are first and foremost concerned with what we think of as physical states, although the distinction may not always be completely clearcut.

Comparing the role of a word such as 'skin' in Kuot and other languages, we found that superficially similar expressions can in fact be quite different, depending on factors such as the scale and elaboration of the domain, culturally mediated notions 
associated with the word in question, and the presence or absence in the language of alternative means of expressing a similar meaning. 


\section{Notes}

1. I wish to thank the Research Centre for Linguistic Typology at La Trobe University (previously at the Australian National University) for the generous support that made fieldwork on Kuot a possibility; as well as the Department of Linguistics at Stockholm University. I also want to thank an anonymous reviewer for suggesting several references and pointing to areas needing discussion, and Sasha Aikhenvald, Tim Curnow and Fritz Serzisko for reading and providing useful feedback on a draft version.

2. It may be worth mentioning here that Kuot, unlike many other non-Austronesian languages in Papua New Guinea, has no specialised experiencer or undergoer constructions, and a concept such as 'I have a headache' is expressed by 'my head hurts', with 'head' as subject of the verb 'hurt, ache' and the person whose head it is as possessor. Nor do Kuot verbs make any distinctions based on the level of control over the situation excercised by the primary argument (cf Foley 1986: 121-127, 190 193).

3. Abbreviations used in Kuot examples and tables are:

$\begin{array}{llll}\text { 1px } & \text { 1st pl exclusive } & \text { O } & \text { object } \\ 1 \mathrm{~s} & \text { 1st sg } & \mathrm{pl} & \text { plural } \\ 3 \mathrm{~d} & \text { 3rd dual } & \text { PossI } & \text { inalienable possessive } \\ 3 \mathrm{f} & \text { 3rd sg feminine } & \text { PossII } & \text { alienable possessive } \\ 3 \mathrm{~m} & \text { 3rd sg masculine } & \text { REC } & \text { reciprocal } \\ 3 \mathrm{p} & \text { 3rd plural } & \text { RED } & \text { reduplication } \\ \text { adj } & \text { adjective } & \text { REFL } & \text { reflexive } \\ \text { ASP } & \text { aspect } & \text { RELR } & \text { relator } \\ \text { COMPL } & \text { complementiser } & \mathrm{S} & \text { subject (tr or itr) } \\ \text { CONT } & \text { continuous aspect } & \text { sg } & \text { singular (f and m) } \\ \text { DEM } & \text { demonstrative } & \text { stm } & \text { 2nd part of V cl III stem } \\ \text { EMPH } & \text { emphatic } & \varnothing & \text { zero subject morpheme } \\ \text { f } & \text { feminine } & - & \text { indivisible morph } \\ \text { FUT } & \text { future/irrealis } & - & \text { affix boundary } \\ \text { HAB } & \text { habitual } & = & \text { clitic boundary } \\ \mathrm{m} & \text { masculine } & <> & \text { hesitation } \\ \text { nsg } & \text { non-singular } & {[]} & \text { (in transl) words in Kuot unidiomatic in } \\ \mathrm{N} & \text { noun } & & \text { English; literal transl. } \\ \mathrm{NW} & \text { north-west } & (\text { ) } & \text { (in transl) words in English not explicit in } \\ & & & \text { Kuot }\end{array}$

4. Reduplication is not uncommon with Kuot verbs, but this is the only example I have where the stem is repeated three times.

5. The corresponding expression in Tok Pisin uses the word 'blut' (<blood): 'blut bilong en i nogut long dispela' (blood POSS 3sg PRED PREP DEM, 'his blood is bad for this').

6. "V" with a roman numeral from I-III refer to the verb classes mentioned in the introduction.

7. Estonian is a Finno-Ugric language closely related to Finnish.

8. Case suffixes are added to the genitive form of the noun. 
9. For a more extensive list, see e.g. Tuldava (1994).

10. 'Blood' in Selepet, apart from it's use for the unformed child, is connected with hunting skills, and the Kuot expression with 'skin' given in (26) above translates into Selepet as 'his blood is dull'. It seems likely that the use of 'blood' in this sense has entered Tok Pisin from Selepet or another language in that region (cf note 5).

11. English words given in single quotes are intended to stand for the indigenous words they translate.

12. The terms for 'shiny (etc.)' and 'dull (etc)' in the Wahgi language are also colour terms. This may be a good place to make the observation that Kuot does not make use of colour symbolism in emotion expressions (unlike e.g. many of the African languages reported by Dimmendaal (this volume)).

13. The Kuots have a very good idea of anatomy. Pigs are usually butchered on the beach and children and others who are not busy with other work frequently stroll by and watch. Further, cannibalism was widespread in the region until some 100 years ago or less, with humans prepared for consumption in the same way as pigs, so there would have been a very clear idea at least among the men also of the anatomical makeup of the human body. (I do not know whether women took part in preparing and/or consuming human flesh.)

14. This analysis differs somewhat from that of Enfield (this volume) who argues that 'heart' as something you buy in the store is more similar to 'heart' in 'I felt my heart pounding' than in 'I felt the deepest passion in my heart'. The difference may be to do with the pounding of the heart being more easily localised than is often the case with a stomach pain. Alternatively, perhaps we should consider a continuum: anatomical reference - physical feeling - emotion.

15. In contrast, traditionally anyone going out on an important fishing expedition (especially for shark), would have to observe a set of taboos for some time beforehand, abstaining from particular foods and from sexual intercourse. Failing to do so would mean that the person would be luckless if going ahead with the venture, but the lucklessness would be temporary, and quite different to the condition described above.

16. A display of sorrow could be controlled of course, but this would normally be expressed by the verb -liba 'cry', or the transitive -aliba 'cry for; mourn'.

17. In a detailed analysis of aleme 'stomach' in the Australian language Kaytetye, Turpin (1997) differentiates (optional) uses of aleme with emotive predicates, calling it metonymically motivated polysemy, from uses with non-emotive predicates, which she calls conventional metonymy. In the former case, the sense of aleme is 'feel; feel deeply' and its use has the effect of making the emotion expressed in the predicate more intense. In the second case, the expressions are idiomatic.

18. This is parallel to the situation in Mangap-Mbula (Bugenhagen 1994). 
19. Kuot would seem to provide a counterexample to Wierzbicka's assertion that "all languages have a word for FEEL, undifferentiated between 'bodily feelings'

(sensations) and 'cognitively based' feelings ('emotions')." (Wierzbicka 1999: 276) 


\section{References}

Bugenhagen, R.D. 1994. "The Exponents of Semantic Primitives in Mangap-Mbula". In C. Goddard and A. Wierzbicka ( eds ), Semantic and Lexical Universals. Amsterdam: John Benjamins

Foley, W.A. 1986. The Papuan Languages of New Guinea: Cambridge Language Surveys. Cambridge: Cambridge University Press.

Goddard, C. 1994. "Lexical Primitives in Yankunytjatjara". In C. Goddard and A. Wierzbicka ( eds ), Semantic and Lexical Universals. Amsterdam: John Benjamins, 229-262.

Goddard, C. 1996. "Cross-Linguistic Research on Metaphor". Language and Communication, 16(2): 145-151.

Lindström, E.C. Forthcoming. A descriptive grammar of Kuot, a non-Austronesian language of New Ireland, Papua New Guinea. Stockholm: Department of Linguistics, Stockholm University (PhD diss.).

McElhanon, K.A. 1975. "Idiomaticity in a Papuan (non-Austronesian) language". Kivung, 8(2): 103-144.

O'Hanlon, M. 1989. Reading the Skin, Adornment, Display and Society among the Wahgi. London: British Museum Publications Ltd.

Strathern, A. 1975. "Why is Shame on the Skin?". Ethnology, 14(4): 347-356.

Strathern, A. 1977. "Why is Shame on the Skin?". In J. Blacking ( ed ), The anthropology of the body. London: Academic Press, 99-110.

Tuldava, J. 1994. Estonian Textbook, Grammar, Exercises, Conversation. Bloomington IN: Indiana University.

Turpin, M. 1997. A syntactic and semantic analysis into aleme 'stomach' in Kaytetye. Canberra: Linguistics, Australian National University (B.A.).

Wierzbicka, A. 1999. Emotions Across Languages and Cultures: Diversity and Universals: Studies in emotion and social interaction, second series. Cambridge: Cambridge University Press.

Eva Lindström is a post graduate student at Stockholm University, and an honorary visiting fellow at the Research Centre for Linguistic Typology at La Trobe University. She is currently writing her PhD dissertation, a descriptive grammar of Kuot based on fieldwork. 